\title{
Tobacco Mosaic Virus Helicase Domain Induces Necrosis in $N$ Gene-Carrying Tobacco in the Absence of Virus Replication
}

\author{
Truus E. M. Abbink, Pernilla A. Tjernberg, John F. Bol, and Huub J. M. Linthorst \\ Institute of Molecular Plant Sciences, Gorlaeus Laboratories, Leiden University, P.O. Box 9502, 2300 RA \\ Leiden, The Netherlands \\ Accepted 2 September 1998.
}

\begin{abstract}
Tobacco mosaic virus (TMV) elicits a hypersensitive response (HR) in tobacco plants that carry the $N$ gene. To identify the elicitor of this HR, Agrobacteriumn tumefaciens was used as a vector for the transient expression of TMV replicase proteins, movement protein, and coat protein in $N N$ and $n n$ tobacco. Transient expression of the $126 \mathrm{~K}$ protein and fragments thereof containing the helicase motifs induced necrosis and systemic expression of the pathogenesis-related PR-1a gene in $N N$ plants but not in $n n$ plants. The results confirm previous evidence that the TMV helicase sequence is the elicitor of the HR (H. S. Padgett, Y. Watanabe, and R. N. Beachy, Mol. Plant-Microbe Interact. 10:709-715, 1997) and demonstrate that this helicase sequence acts as an elicitor of $\mathrm{HR}$ in the absence of other viral proteins or RNA replication.
\end{abstract}

Tobacco mosaic virus (TMV) belongs to the family of tobamoviruses. Its genome consists of a single-stranded RNA molecule of positive polarity and contains three open reading frames (ORFs). The most upstream ORF encodes the 126K protein and by readthrough of an amber stop codon also the $183 \mathrm{~K}$ protein. Both these proteins constitute the viral replicase. Three putative domains have been identified in the $126 \mathrm{~K}$ and $183 \mathrm{~K}$ proteins: the methyl transferase domain, the helicase domain, and, uniquely in the $183 \mathrm{~K}$ protein, the GDD motif, required for RNA polymerase function. The two downstream ORFs encode the movement protein (MP) and the coat protein (CP). These proteins are translated from subgenomic mRNAs (Van Regenmortel and Meshi 1995).

TMV infection of Nicotiana tabacum leads to a hypersensitive response (HR) if the plant's genome contains the $N$ gene (Whitham et al. 1994). As a consequence, the virus is confined to the vicinity of the necrotic lesions and cannot spread systemically through the plant. In addition, the plant becomes resistant to a broad spectrum of pathogens, including bacteria, fungi, and viruses. This phenomenon is known as systemic acquired resistance (SAR; Ryals et al. 1996). N. tabacum plants that lack the $N$ gene do not induce an HR upon TMV

Corresponding author: H. J. M. Linthorst

E-mail: linthors@chem.leidenuniv.nl infection, nor acquire systemic resistance. TMV spreads systemically throughout these plants.

During the HR several physiological alterations occur in the plant cell (reviewed by Staskawicz et al. 1995). Interestingly, several genes are induced in cells surrounding the necrotic lesions. Among them are the pathogenesis-related (PR) genes (Linthorst 1991). PR proteins can be divided into acidic and basic PR proteins. The acidic PR proteins are located extracellularly, while basic PR proteins are located in vacuoles. After TMV infection of $N$ gene-carrying tobacco plants, both acidic and basic PR proteins are induced in inoculated leaves, while in uninfected systemic leaves predominantly the acidic PR proteins are induced. In tobacco plants that lack the $N$ gene, PR genes are not induced upon TMV infection (Linthorst 1991).

The $N$ gene has been cloned (Whitham et al. 1994). The size of the $N$ gene product is $131.4 \mathrm{kDa}$, and due to the lack of any known signal sequences the $\mathrm{N}$ protein is likely located in the cytoplasm. The amino-terminus of the protein shows homology to the Drosophila melanogaster Toll protein and the mammalian interleukin-1 receptor. A putative nucleotidebinding motif has been identified and 14 leucine-rich repeats are present in the carboxy-terminus of the protein. These features make the $\mathrm{N}$ protein a suitable candidate for a role in signal transduction. The current hypothesis is that a TMV protein can interact directly or indirectly with the $\mathrm{N}$ protein and thereby activate a signal transduction pathway leading to HR, PR gene induction, and SAR.

To identify the TMV elicitor of the HR in $N$ gene-carrying tobacco, we expressed the TMV ORFs in Samsun NN plants with a transient expression system based on the T-DNA transfer of Agrobacterium tumefaciens. This system excludes any direct or indirect effect of viral replication on the induction of HR. This system has been used successfully by others to identify AvrPto as the HR elicitor in bacterial speck disease (Scofield et al. 1996; Tang et al. 1996).

Oligonucleotide primers were designed to create, by polymerase chain reaction, TMV ORF constructs with $N c o$ I sites at the initiation codon and PstI sites downstream of the stop codon. We cloned the TMV ORFs (126K, 183K, MP, and CP), shown in Figure 1, under the control of the constitutive $35 \mathrm{~S}$ promoter in the pMOG800 binary vector (Knoester et al. 
1998). The resulting clones were named pMOG-126K, pMOG-183K, etc. After transformation, A. tumefaciens cultures containing $100 \mathrm{mM}$ acetosyringone were infiltrated into Samsun NN tobacco plants, essentially as described (Schöb et al. 1997). Approximately 1 week post infiltration (p.i.), expression of the $126 \mathrm{~K}$ ORF resulted in leaf yellowing, which turned necrotic in the next 3 days (Fig. 2). The yellowing and necrosis corresponded to the infiltrated areas of the leaf. Also, the necrotic reaction was dependent on the presence of the $N$ gene, since expression of $126 \mathrm{~K}$ in Samsun nn plants not containing the $N$ gene did not result in necrosis (Fig. 2A). The infiltration of A. tumefaciens itself or A. tumefaciens transformed with the empty vector did not induce necrosis or leaf yellowing, ruling out any necrotic response to the infiltration procedure or A. tumefaciens (Figs. 2A and 3A). Apparently, $126 \mathrm{~K}$ expression induced an HR in Samsun NN, even in the absence of other TMV proteins or viral RNA replication.

Subsequently, we expressed carboxy-terminal regions of the 126K ORF containing the putative RNA helicase domain. Internal methionine codons (nucleotide positions 2109 and 2484 in the TMV genome) within the $126 \mathrm{~K}$ ORF were used as initiation codons for these truncated proteins, which were designated MOREHEL and HEL, respectively (Fig. 1). In Samsun NN plants, expression of MOREHEL resulted in a rapid and massive necrosis within 3 days p.i. that was not visibly preceded by leaf yellowing (Fig. 2). Again, the necrotic reaction was not observed in Samsun nn plants and was therefore specific for the presence of the $N$ gene. Expression of HEL resulted in a slower response and induced necrosis approximately 2 weeks p.i. (Fig. 2). Similar to expression of the $126 \mathrm{~K}$ ORF, this necrosis was preceded by leaf yellowing and was not induced in Samsun nn plants. In view of these data, it is obvious that the methyltransferase domain is dispensable for HR induction.

Since expression of MOREHEL gave the most rapid necrotic response, we used this ORF for further studies. To discriminate between the possibility of MOREHEL RNA or MOREHEL protein being the elicitor of the necrotic response, we constructed +1 and -1 frameshift mutants of the MOREHEL ORF that can express RNA, but cannot produce
MOREHEL protein. Three independent mutants were obtained with frameshifts located 41 or 87 nucleotides downstream of the MOREHEL initiation codon. Infiltration of these MOREHEL frameshift mutants in Samsun NN plants did not induce necrosis or leaf yellowing, indicating the requirement of the MOREHEL protein in elicitor function (data not shown).

Our data support the results obtained by Padgett et al. (1997), who used a viral expression system based on the nonHR-inducing Ob strain of TMV to identify the TMV elicitor in transgenic MP Xanthi nc tobacco. However, their data showed that expression of the HEL equivalent did not induce necrosis while expression of the MOREHEL equivalent did. The reason for the discrepancy with our results may be due to differences in expression of the HEL sequence from the TMV or A. tumefaciens vector, the transgenic expression of MP in the Xanthi nc plants, or differences in the genetic background of Samsun NN and Xanthi nc tobacco. Obviously, the A. tumefaciens-mediated expression system supports a model in which expression of HEL-containing proteins is the single prerequisite for HR induction in $N$ gene-carrying tobacco. In our studies, necrosis induced by HEL, MOREHEL, or $126 \mathrm{~K}$ is independent of virus replication.

Expression of the TMV MP or CP did not induce necrosis in Samsun NN plants. Surprisingly, neither did expression of the $183 \mathrm{~K}$ ORF encoding both the $126 \mathrm{~K}$ and the $183 \mathrm{~K}$ proteins (Fig. 2B). Possibly, T-DNA transfer of the intact $183 \mathrm{~K}$ ORF with a size of $4.9 \mathrm{~kb}$ is inefficient, which results in $126 \mathrm{~K}$ and $183 \mathrm{~K}$ protein levels too low to induce necrosis. It is generally accepted that the efficiency of $A$. tumefaciens-mediated stable transformation is inversely proportional to the size of the constructs used (Risseeuw et al. 1996). The transient expression of TMV $126 \mathrm{~K}$ protein, $183 \mathrm{~K}$ protein, MP, and CP in A. tumefaciens-infiltrated tissue was too low to be detected by immunoblotting with the available antisera (data not shown). The $35 \mathrm{~S}$ promoter is known to be functional in A. tumefaciens (Vancanneyt et al. 1990). As a consequence, the presence of the $126 \mathrm{~K}$ protein in pMOG-183K-transformed A. tumefaciens cultures was detected by Western blotting with antiserum against TMV $126 \mathrm{~K}$. The $183 \mathrm{~K}$ protein was not detected in
TMV genome

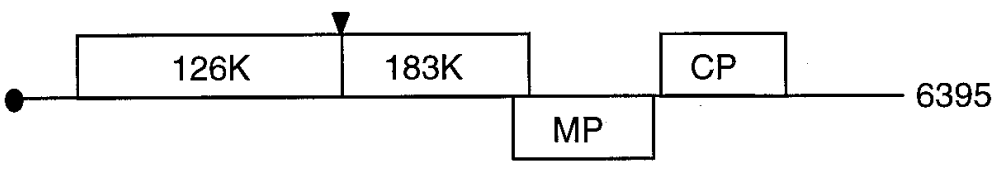

$183 \mathrm{~K}$
$126 \mathrm{~K}$
MOREHEL
HEL
MP
CP

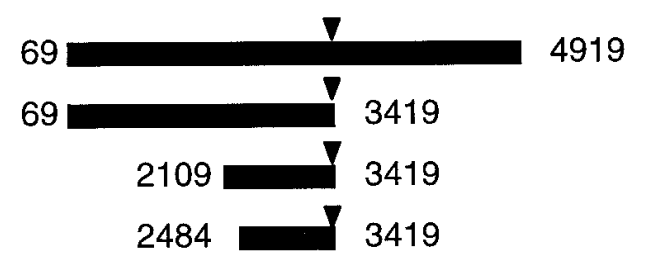

$4903 \square 5709$

$5711 \square 6191$

Fig. 1. Schematic representation of TMV-U1 genome and the tobacco mosaic virus (TMV) open reading frames (ORFs) used for Agrobacterium tumefaciens-mediated expression. MOREHEL and HEL are constructs expressing partial TMV proteins and were engineered from the 126K/183K ORF. The amber stop codon (nucleotide position 3419) is indicated with a black triangle. In the 126K, MOREHEL, and HEL constructs an engineered UAA stop codon followed the original amber stop codon. Figures indicate the positions of the $5^{\prime}$ and $3^{\prime}$ nucleotides of each construct. 


\section{A}

nn
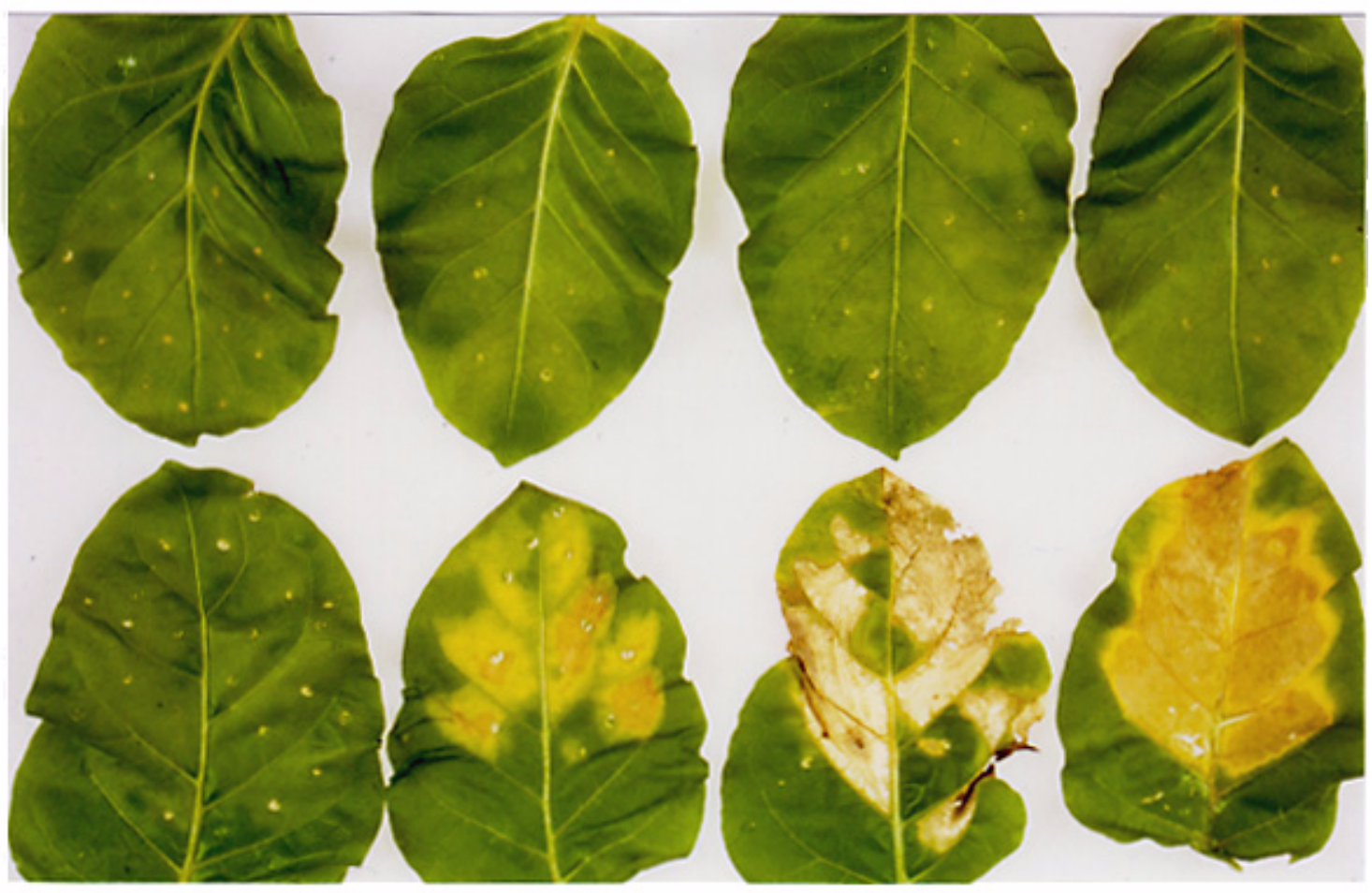

A. tum.

HEL

MOREHEL

126K

B
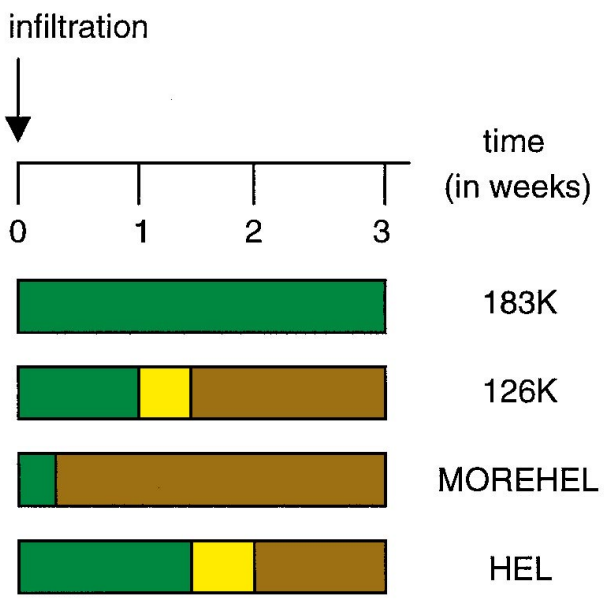

HEL

MP

CP

Fig. 2. Expression of tobacco mosaic virus (TMV) open reading frames (ORFs) in Nicotiana tabacum plants. Plants were infiltrated with transformed Agrobacterium tumefaciens cultures and observed for 3 weeks. A, Leaf symptoms upon transient expression of TMV ORFs. Cultures used for infiltration are indicated at bottom of photograph (A.tum: nontransformed A. tumefaciens; HEL: A. tumefaciens transformed with pMOG-HEL; MOREHEL: A. tumefaciens transformed with pMOG-MOREHEL; 126K: A. tumefaciens transformed with pMOG-126K). NN and nn denote Samsun NN and Samsun nn leaves. Photograph was taken 2 weeks post infiltration. B, Time course of leaf symptoms after transient expression of TMV ORFs in Samsun NN plants. TMV ORFs are indicated at right. Color corresponds to appearance of the infiltrated leaf area (green: invisible symptoms to light chlorosis; yellow: yellowing; brown: necrosis). Infiltrated leaf area was observed for a 3-week period. 
pMOG-183K-transformed A. tumefaciens, in which readthrough of the UAG amber termination codon of the $126 \mathrm{~K}$ ORF probably does not occur. As induction of necrosis in $N N$ tobacco by $A$. tumefaciens-mediated expression of $126 \mathrm{~K}$,

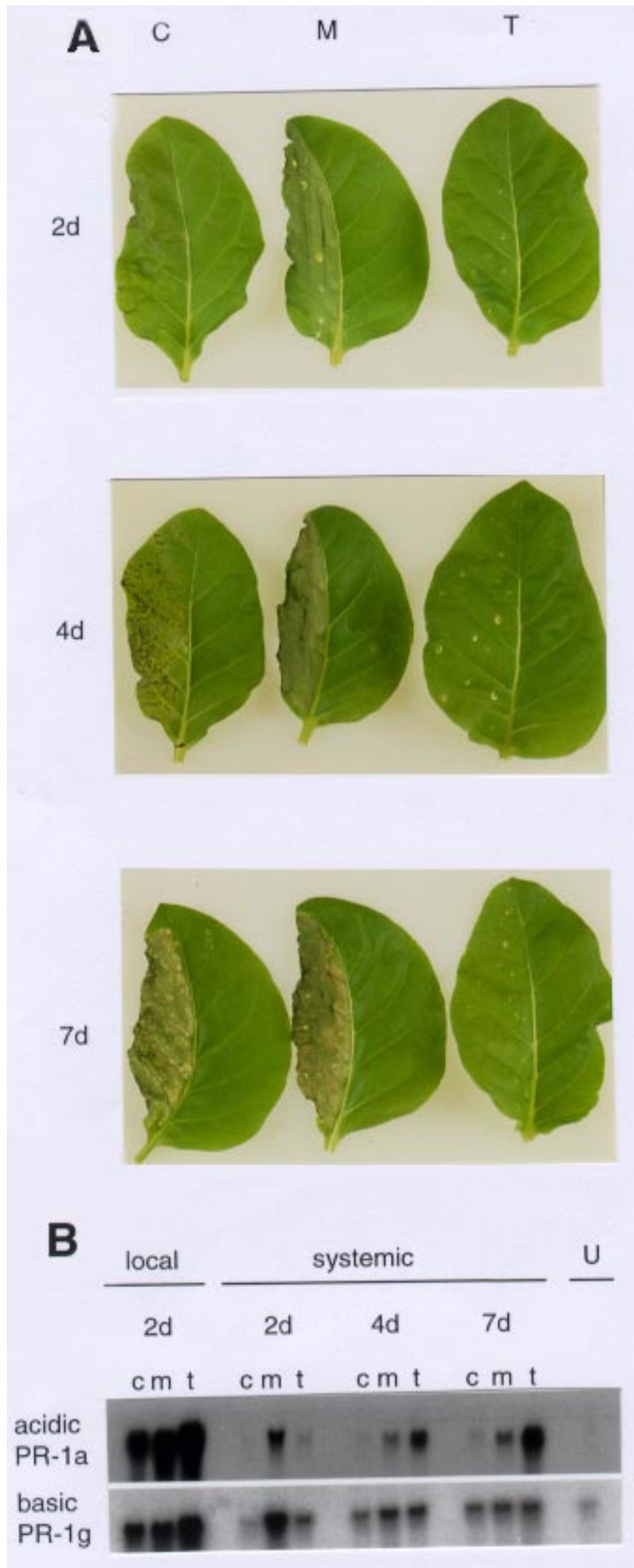

MOREHEL, and HEL proteins was abolished when acetosyringone was omitted from the infiltration medium (data not shown), the elicitation of HR was probably mediated by proteins expressed from T-DNA transferred to plant cells rather than by proteins expressed from T-DNA in the bacterium. This dependency on acetosyringone emphasizes the need for efficient T-DNA transfer.

The next question we addressed was whether the MOREHEL protein could induce local and systemic PR gene expression in Samsun NN plants, as is observed upon TMV infection. Thus, we infiltrated leaf halves of Samsun NN plants with either MOREHEL- or empty vector-transformed $A$. $t u$ mefaciens. In addition, leaf halves were infected with TMV as a positive control. Expression of MOREHEL induced necrosis after 2 days, while infection with TMV resulted in small necrotic lesions that expanded during the course of the experiment (Fig. 3A). At several time points, total RNA from the locally infiltrated and the systemic, noninfiltrated leaf halves was isolated and analyzed by Northern blots for PR-1 gene expression (Brederode et al. 1991; Memelink et al. 1989).

With the acidic PR-1a and the basic PR-1g cDNAs as probes, Northern blot analysis revealed that in local leaf halves both PR-1 genes were induced after infiltration with empty vector-transformed A. tumefaciens (Fig. 3B). Apparently, A. tumefaciens infiltration was capable of triggering local PR-1 gene transcription. This induction of PR gene expression was also observed in Samsun nn plants. Therefore, this local induction is not mediated by the $N$ gene. It has been shown by others that $A$. tumefaciens induces local glucanase and chitinase gene expression after infiltration in N. sylvestris (Schöb et al. 1997).

Expression of MOREHEL resulted in a rapid, systemic, PR1a gene induction, which did not occur in leaves that were infiltrated with empty vector-transformed $A$. tumefaciens (Fig. 3B). This systemic PR-1a gene induction by MOREHEL was not observed in Samsun nn plants (data not shown), indicating that the induction in the NN plants is clearly mediated by the product of the $N$ gene. Also, MOREHEL transiently elevated the expression of basic PR-1g gene in systemic leaf halves 2 days p.i. This expression returned to basal levels at later time points. Significant systemic PR-1g gene induction was not observed upon TMV infection or infiltration with empty vector-transformed $A$. tumefaciens. The transient systemic induction of PR-1g after expression of MOREHEL may be due to the rapid and massive necrosis in the opposite leaf half. HRs

Fig. 3. Local and systemic induction of acidic and basic PR-1 in Samsun NN plants by MOREHEL expression and tobacco mosaic virus (TMV) infection. Leaf halves were infiltrated with Agrobacterium tumefaciens transformed with the empty vector as a negative control (C), with $A$. tumefaciens transformed with pMOG-MOREHEL (M) or infected with TMV as a positive control (T). Leaves were photographed 2, 4, and 7 days after treatment $(2 \mathrm{~d}, 4 \mathrm{~d}$, and $7 \mathrm{~d})$, after which inoculated and noninoculated leaf halves were separated. For each treatment, six leaf halves originating from two plants were pooled at indicated time points (local leaf halves were only isolated 2 days after treatment, since MOREHEL expressing leaf halves turned completely necrotic at later time points). Total RNA was isolated, electrophoresed, blotted, and hybridized with PR-1a (acidic) and PR-1g (basic) cDNA probes. A, Symptoms during course of the experiment. B, Northern (RNA) blot analysis of PR-1a and PR-1g mRNA accumulation upon MOREHEL expression. Expression of the PR-1a and PR-1g genes in untreated leaves is shown in lane U. 
result in a burst of ethylene, which is a potent inducer of basic PR genes (Brederode et al. 1991; Ecker 1995). In TMVinfected leaf halves, necrotic lesions are dispersed within healthy tissue. The lesions slowly increase in size during the course of the experiment. Therefore, ethylene production may be more gradual and not affect systemic PR-1g gene expression in the opposite leaf half.

In conclusion, our data further support the notion that the necrosis induced by the MOREHEL sequence parallels the characteristics of the HR induced by a complete TMV infection and that the MOREHEL sequence alone is sufficient to trigger signal transduction pathway(s) leading to PR gene expression.

As was shown for HR elicitors from other pathogens (Scofield et al. 1996; Tang et al. 1996), the A. tumefaciensmediated transient expression system proved a successful and reliable technique to identify the TMV elicitor in $N$ genecarrying tobacco plants. Using the yeast two-hybrid system, we are currently screening a Samsun NN cDNA library to identify host proteins that interact with the MOREHEL protein. These interacting proteins may play a role in host recognition of the TMV helicase domain in Samsun NN plants or may be involved in TMV replication.

\section{ACKNOWLEDGMENTS}

We would like to thank David Baulcombe for providing us the protocol for the Agrobacterium tumefaciens-mediated expression system and Roger Beachy for supplying the $126 \mathrm{~K}$ antiserum. This research was supported by the Life Sciences Foundation (S. L. W.), which is subsidized by the Netherlands Organization for Scientific Research (N. W. O.).

\section{LITERATURE CITED}

Brederode, F. T., Linthorst, H. J. M., and Bol, J. F. 1991. Differential induction of acquired resistance and PR gene expression in tobacco by virus infection, ethephon treatment, UV light and wounding. Plant Mol. Biol. 17:1117-1125.

Ecker, J. R. 1995. The ethylene signal transduction pathway in plants. Science 268:667-675.

Knoester, M., Van Loon, L. C., Van Den Heuvel, J., Hennig, J., Bol, J.
F., and Linthorst, H. J. M. 1998. Ethylene-insensitive tobacco lacks nonhost resistance against soil-borne fungi. Proc. Natl. Acad. Sci. USA 95:1933-1937.

Linthorst, H. J. M. 1991. Pathogenesis-related proteins of plants. Crit. Rev. Plant Sci. 10:123-150.

Memelink, J., Swords, K. M. M., Staehlin, L. A., and Hoge, J. H. C. 1994. Southern, Northern, and Western blot analysis. Pages F1-F23 in: Plant Molecular Biology Manual. S. B. Gelvin and R. A. Schilperoort, eds. Kluwer Academic Publishers, Dordrecht, The Netherlands.

Padgett, H. S., Watanabe, Y., and Beachy, R. N. 1997. Identification of the TMV replicase sequence that activates the $N$ gene-mediated hypersensitive response. Mol. Plant-Microbe Interact. 10:709-715.

Risseeuw, E., Franke-van Dijk, M. E. I., and Hooykaas, P. J. J. 1996. Integration of an insertion-type transferred DNA vector from Agrobacterium tumefaciens into the Saccharomyces cerevisiae genome by gap repair. Mol. Cell. Biol. 16:5924-5932.

Ryals, J. A., Neuenschwander, U. H., Willits, M. G., Molina, A., Steiner, H.-Y., and Hunt, M. D. 1996. Systemic acquired resistance. Plant Cell 8:1809-1819.

Schöb, H., Kunz, C., and Meins, F., Jr. 1997. Silencing of transgenes introduced into leaves by agroinfiltration: A simple, rapid method for investigating sequence requirements for gene silencing. Mol. Gen. Genet. 256:581-585.

Scofield, S. R., Tobias, C. M., Rathjen, J. P., Chang, J. H., Lavell, D. T., Michelmore, R. W., and Staskawicz, B. J. 1996. Molecular basis of gene-for-gene specificity in bacterial speck disease of tomato. Science 274:2063-2065.

Staskawicz, B. J., Ausubel, F. M., Baker, B. J., Ellis, J. G., and Jones, J. D. G. 1995. Molecular genetics of plant disease resistance. Science 268:661-666.

Tang, X., Frederick, R. D., Zhou, J., Halterman, D. A., Jia, Y., and Martin, G. B. 1996. Initiation of plant disease resistance by physical interaction of AvrPto and Pto kinase. Science 274:2060-2063.

Van Regenmortel, M. H. V., and Meshi, T. 1995. Genus Tobamovirus. Pages 434-437 in: Virus Taxonomy. Classification and Nomenclature of Viruses: Sixth Report of the International Committee on Taxonomy of Viruses, F. A. Murphy, C. M. Fauquet, D. H. L. Bishop, S. A. Ghabrial, A. W. Jarvis, G. P. Martelli, M. A. Mayo, and M. D. Summers, eds. Springer-Verlag, Vienna.

Vancanneyt, G., Schmidt, R., O'Connor-Sanchez, A., Willmitzer, L., and Rocha-Sosa, M. 1990. Construction of an intron-containing marker gene: Splicing of the intron in transgenic plants and its use in monitoring early events in Agrobacterium-mediated plant transformation. Mol. Gen. Genet. 220:245-250.

Whitham, S., Dinesh-Kumar, S. P., Choi, D., Hehl, R., Corr, C., and Baker, B. 1994. The product of the tobacco mosaic virus resistance gene $N$ : Similarity to Toll and the Interleukin-1 receptor. Cell 78: 1101-1115.

\section{Erratum, Volume 11 no. 12, 1998}

In the paper by Truus E. M. Abbink, Pernilla A. Tjernberg, John F. Bol, and Huub J. M. Linthorst (12:1242-1246) entitled "Tobacco Mosaic Virus Helicase Domain Induces Necrosis in $N$ GeneCarrying Tobacco in the Absence of Virus Replication" there is an error in Figure 3A. The letters above the three sets of three leaves should be re-ordered from C M T to T M C. 